\title{
THE ANALYSIS OF NURSING CARE DOCUMENTATION IN OUTPATIENT UNITS
}

\section{Any Kurniawati ${ }^{1}$, Agustin Indracahyani ${ }^{2}$, Aat Yatnikasari $^{3}$}

\section{Postgraduate student of Leadership and Management of Nursing, Faculty of Nursing Science, Universitas Indonesia, Depok \\ 2. DKKD Faculty of Nursing Science, Universitas Indonesia, Depok \\ 3. Committee of Nursing in Harapan Kita Mother and Child Hospital \\ * Correspondence: any_kurniawati@yahoo.com}

\begin{abstract}
Outpatient units have high activity and interaction, which increases the risk of neglecting full documentation of nursing care. This study aims to analyze factors contributing to the lack of optimal documentation of nursing care in an outpatient unit. This study employed a fish bone analysis approach to identify the root of problems of documenting nursing care in an outpatient unit. This research was conducted in an outpatient unit of the Children's and Mother's Hospital in Jakarta. The data collection techniques of this study were questionnaires, observations, and interviews with the head of the room, Clinical Instructors, implementing nurses, Case Managers, and Nursing Fields. The analysis reveals several results. Nurses, clinical instructors, activities in high work environments, as well as policies and tools for assessment and supervision are inadequate. The absence of effective systems and mechanisms for supervising nursing care documentation and manual documentation systems contributes to the lack of optimal documentation of nursing care in the outpatient unit. Documentation of nursing care extremely depends on workforce, work climate, sets of policies, systems, and facilities. This study recommends programs and supervision activities for outpatient nursing care documentation performed by the Nursing Division, head of rooms, and Clinical Instructors, arranges supervision tools, arranges patients' effective and efficient assessment documentation according to accreditation, policy resocialization and documentation techniques, as well as energy management and implementation time documentation of nursing care in an outpatient unit.
\end{abstract}

Keywords: clinical instructors, outpatient unit, nursing care, nursing documentation, supervision nursing care documentation.

International Journal of Nursing and Health Services (IJNHS), September 2019, Volume 2, Issue 3; Page 89-99

Received: 28 March 2019; Revised: 16 April 2019; Accepted: 19 April 2019

DOI: http//doi.org/10.35654/ijnhs.v2i3.97

\section{Introduction}

Documentation is one of the key aspects to provide safe and qualified nursing care. American Nurses Association (2010) states that clear, accurate, and accessible documentation is the most important elements of proof, safety, and quality-based nursing practice (1). Documentation becomes legal proof in the conflicting situation of ethics and law (2). An accurate document is one of the best self-defences to the requirement related to nursing care.

Though documentation is an important aspect, some people consider that it 
increases nurses' workload and the nurses' attitudes to the documentation influence the documentation quality (3). Documentation will increase nurses' workload because they have little time (4). A study from Kent \& Morrow (2014) Patients' and nurses' ratio factors influence the workload which results in non-optimal documentation (5). Documentation of nursing care still has various factors of obstacles, and thus, it requires attention to increase the documentation.

Documentation in outpatient units requires particular attention. The implementation of documentation is nearly incomplete in all steps of caring process, especially in the analysis and evaluation process. Therefore, documentation requires improvement in its implementation. Documentation of nursing care, particularly of analysis by implementing format of Integrated Patients' Improvement Record (IPIR) and reassessment, in outpatient units of X Mother and Child Hospital (RSAB X) is not optimally implemented.

Some researches assert that non-optimal documentation is caused by several factors: limitation of time, workload, attitude, and institution's policy related to nonoptimal nursing care documentation (3). Another obstacle is nurses' comprehension of the importance of nursing care documentation (6). Several factors of non-optimal nursing care documentation are necessarily identified to solve the problems.

Fishbone analysis is broadly employed to identify the root causes that occur in a health service facility. The analysis is conducted to increase safety and caring quality (7). Fishbone analysis is a structured process which helps to identify factors causing the problems and improve the action to solve the problems (8). The causes of nonoptimal documentation in outpatient are analyzed by fishbone analysis.

A mother and child hospital has unique characteristics because it involves parents to provide nursing care. Therefore, it becomes nurses' challenge to provide patient and family-centred nursing care besides the complete documentation. An outpatient room has high activities and interactions that require the nurses to work effectively in a short time. Consequently, several impacts of nursing care and documentation are ignored.

Several unique characteristics of an outpatient unit in RSAB X is one of the factors intriguing the researchers to analyze contributing factors of non-optimal nursing care documentation by employing fishbone analysis.

The researchers realize the importance of optimizing nursing care documentation. Therefore, the researchers emphasize the importance of nursing care documentation evaluation in outpatient units of RSAB X.

\section{Objective}

The objective of this research is to identify the factors associated with nonoptimal nursing care documentation in outpatient units of RSAB X Jakarta.

\section{Method}

This research employed fishbone analysis consisting of Man, Method, Material, Machine, and Environment. Fishbone analysis was employed to examine the root causes of non-optimal nursing care documentation in the outpatient unit. This research is an innovation legalized by a permit Number DM.05.02/11/3019/2018 to collect data and publish the research result conducted in Mother and Child Hospital Class A in Jakarta 


\section{Data Collecting Techniques}

The researchers collected the primary data by interview, observation, and questioner. This research's interviewees were head of nurses, clinical instructors, case manager, and head of nursing sector. Meanwhile, the observed objects were services and documentation of 4 polyclinics during 4 days; and the observation length was 2 hours in each polyclinic. The observed medical record documents were 40 . The questionnaire consisted of 40 questions related to motivation in nursing documentation.

\section{Data Analysis}

The researchers applied five systematic steps, objective identification, literature review, data collection, data analysis and recommendation for improving the quality of nursing care documentation in outpatient units. The collected data were analyzed by fishbone analysis consisting of five domains: man, environment, method, material, machine, and environment.

\section{Result}

The Characteristics of Outpatient Rooms in RSABX

The outpatient units are divided into general outpatient department, children's outpatient department, mother's outpatient department, as well as dental and oral care outpatient department. A head of nurse who is responsible for nursing services leads each room. Meanwhile, clinical instructors are responsible for nursing care. The outpatient unit has some experts: 4 heads of nursing, 3 clinical instructors (CI), and 37 nurses. The nurses' characteristics are presented in table 1.

Table 1 . The characteristics of nurses $(n=37)$

\begin{tabular}{lrr}
\hline Characteristics & $\mathrm{N}$ & $\%$ \\
\hline Ages (years) & & \\
$<25$ & 4 & 11 \\
$25-35$ & 10 & 27 \\
$36-45$ & 11 & 30 \\
$46-50$ & 5 & 13 \\
$\quad>50$ & 7 & 19 \\
\hline Education & & \\
$\quad$ Bachelor of Nursing & 9 & 24 \\
$\quad$ Associate's Degree of & 26 & 70 \\
$\quad$ NursingDiploma of Nursing & 2 & 6 \\
\hline Career ladder & & 21 \\
$\quad$ Pra PK & 8 & 19 \\
$\quad$ PK I & 7 & 11 \\
PK II & 4 & 49 \\
$\quad$ PK III & 18 & \\
$\quad$
\end{tabular}


Diagram 2. The Organizational Structure of Outpatient Unit

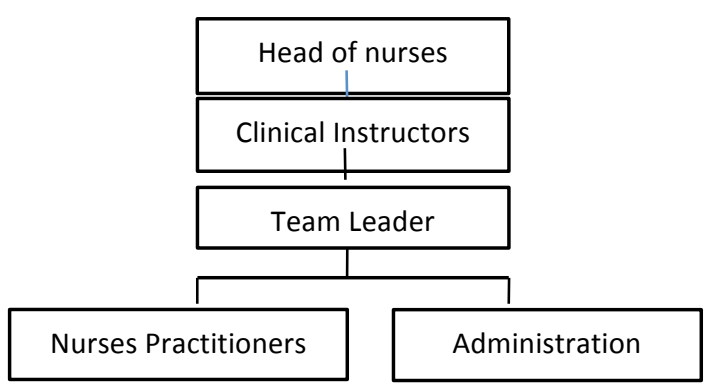

The research conducted in X Mother and Child Hospital reveals several results. :

\section{Interview}

The interviewees of this research are with 4 heads of nurses, 3 clinical instructors, a case manager, and a head section of nursing caring.

There are 24 active outpatient polyclinics with 430 visitors per day. The result of the independent observation of the patients' waiting time in 2017 is 59 minutes. The delays of doctor's practice causes patient stack particularly at 9 a.m. -2 p.m., and thus, the nurses are busy at the time.

The policies of nursing care documentation in outpatient units are Standard Operating Procedures (SOP) of Outpatient Service Flow and Accreditation Standards. The SOP states that documentation format of nursing care in outpatient units employs a format of Integrated Patient Record with note taking method of SOAP (Subjective, objective, Analysis, and Planning). Nursing reassessment employs an integrated-initial assessment format.

Documentation should be complete, but, in fact, the data frequently document the height and weight. The assessment of new symptoms employs data of body temperature measurement, while blood pressure measurement on kids more than 12 years is non-optimal. Patients' reassessment is not implemented as standard.

The nurses still necessarily increase their comprehension and obedience from nursing care documentation. A training program on documentation is conducted, but it is not specific to outpatients' documentation. Supervision program of documentation form the Nursing Sector does not exist because the hospital still prioritizes inpatient areas.

Supervision is not programmed, and the implementation by Clinical Instructors (CI) is non-optimal because of big number of patients and inadequate time to supervise. Integrated assessment format is less practical. The process of documenting does not employ electronic tools.

\section{Observation}

The observation data related to nursing care services and documentation show that documentation record of improvement completed in CPPT is only $30 \%$. The documentation data does not include SOAP, but only includes subjective and objective data of patients' height and weight. Blood pressure measurement on children above 12 years old is not conducted. Reassessment documentation is not implemented 
consistently.

The result of observing activities of heads of nurse and clinical instructors reveals that $50 \%$ head of nurse and $50 \%$ of clinical instructors conduct direct supervision to documentation. Standard Operating Procedures (SOP) of Outpatient Service Flow is available. Another accreditation-based policy is employed to organize

The report of scientific nursing meeting states that there are 10 materials of documentation nursing care during 2016-2018, but the meeting does not discuss documentation of nursing care in outpatient units. Documents of patients' medical record are provided to health staff lately, and thus, they use a blank paper.

\section{Questionnaire}

The result of questionnaires shows that:

1) $81.8 \%$ of the staff state that they always document the result of assessment by using the SOAP method in CPPT correctly;

2) $50 \%$ of heads of nurses and $50 \%$ of clinical instructors state that they supervise the documentation of nursing care;

3) $75 \%$ of heads of nurses always involve Clinical Instructors in monitoring the completeness of documentation;

4) $75 \%$ of heads of nurses state that they always facilitate employee fulfilment and $75 \%$ of nurses have excessive workload; and

5) $75 \%$ of nurses argue that they complete the documentation though it is nonoptimal because of their inadequate time complete patients' improvement and reassessment records.

The analysis result is described in diagram 3 
Diagram 3. Fishbone Analysis

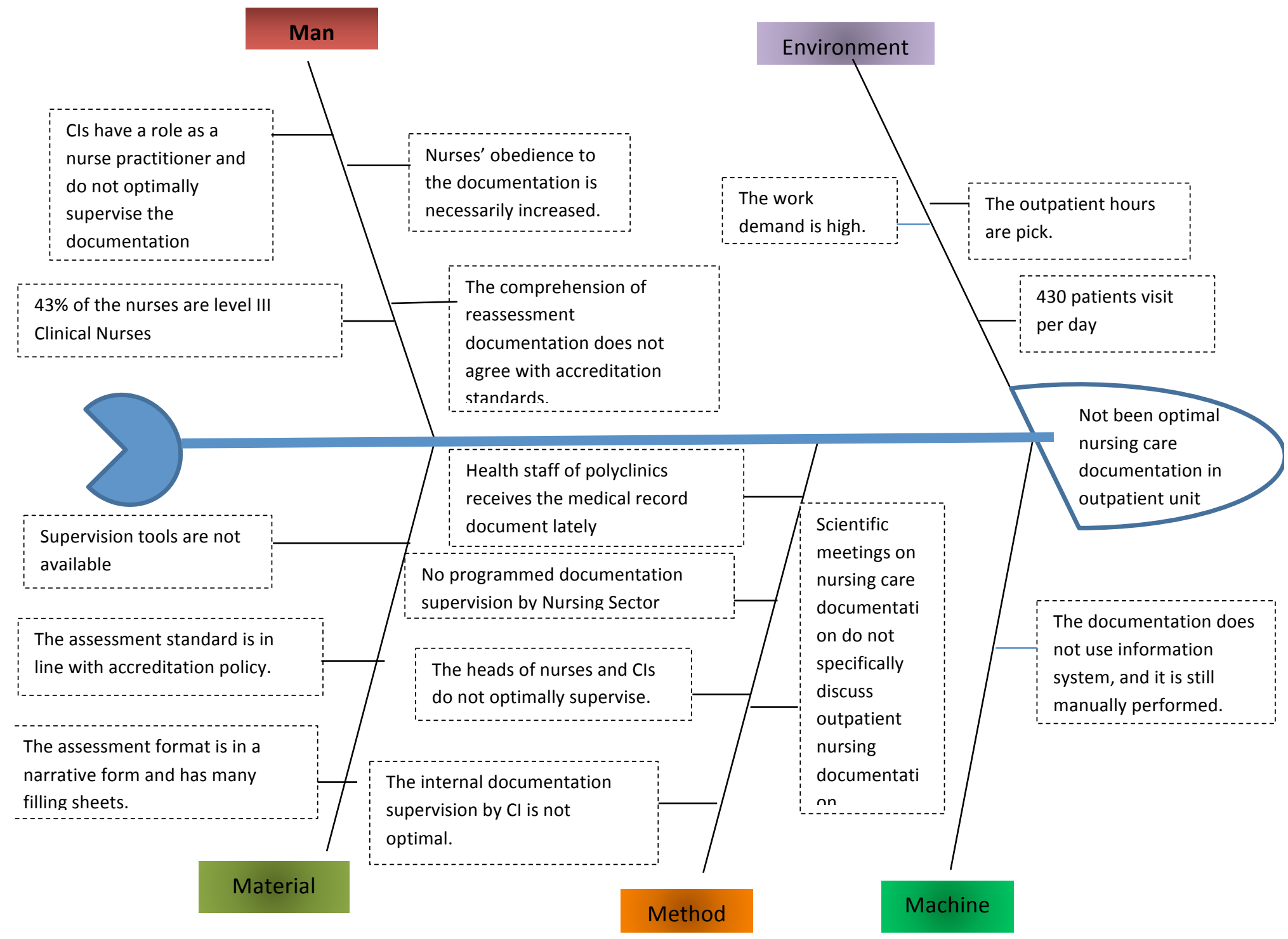

The causes of non-optimal nursing care documentation in the outpatient units are presented in Table 2 :

Table 2. Result of Fishbone Analysis

\begin{tabular}{|c|c|}
\hline Domain & Causes \\
\hline Man & $\begin{array}{l}\text { - Nurses' obedience to the documentation is necessarily increased. } \\
\text { - The comprehension of reassessment documentation does not agree } \\
\text { with accreditation standards. } \\
\text { - CIs have a role as a nurse practitioner, and they argue that they do } \\
\text { not optimally supervise the documentation. } \\
\text { - } 43 \% \text { of the nurses are competent nurses }\end{array}$ \\
\hline
\end{tabular}

Environment - The outpatient hours are pick. 
- 430 patients visit per day.

- The work demand is high.

Material - The assessment standard is in line with accreditation policy.

- The assessment format is in a narrative form and has many filling sheets.

- Supervision tools are not available.

Method - The medical record documentation is received by health staff of polyclinics lately, and thus, the administration pages are used.

- The documentation supervision of nursing care by nursing sectors is not programmed.

- The internal documentation supervision by CI is not optimal.

- The heads of nurses and CIs do not optimally supervise.

- Scientific meetings on nursing care documentation do not specifically discuss outpatient nursing documentation.

Machine

- The documentation does not use information system, and it is still manually performed.

\section{Discussion}

Documentation of outpatient nursing assessment is regulated in accreditation standards. JCI through Standard Assessment of Patients (AOP.1) regulates the initial assessment process to identify the health care needs of all patients (9). While the time frame for the initial assessment according to SNARS in Standard AP.1.2 is carried out for new patients, patients with new diagnoses, and patients with similar diagnosis at the second visit to that at longtime spacing, according to hospital regulation more than one month for an acute diagnosis, or three months for a chronic disease (10). Reassessment is important to understand patients' responses to care, treatment, and service, and it is important to determine whether care decisions are adequate and effective (10).

Documentation contributes to the quality of nursing care. Nursing documentation is frequently considered as insignificant because handwriting of nursing report is considered as a nurse's ritual and information provided is inadequate. Furthermore, nursing documentation in outpatient care contributes to the quality of nursing care. Assessment of patient documentation and assessment in outpatient care are needed to determine changes in the patient's condition (11). Good clinical assessment is important to develop a treatment plan and monitor or identify changes in the patient's condition (12). Patient assessment and reassessment are necessary data for patient care decisions.

The documentation of outpatient nursing care in RSAB X is $30 \%$ completed in integrated progress notes. Documentation should be complete, but documented data only record height and weight. Data for assessing new vital signs of body temperature measurement is optimally recorded while blood pressure in children over 12 years old is not optimally recorded. Patient reassessment has not been carried out according to standards. The documentation standard for outpatient nursing care is in the Standard Operating Procedures for Outpatient Services and SNARS. The Standard Operating Procedures Outpatient Service Flow explains that the initial assessment employs an integrated assessment format, while the routine assessment employs the development note sheet with the Subjective, Objective, Analysis and Planning (SOAP) method.

Fishbone analysis reveals several causes of non-optimal nursing documentation in RSAB X. First, outpatient relates to nurses' understanding and compliance regarding 
documentation of nursing care. Second, the nurses have high workloads. Three, specific training programs on outpatient documentation are never conducted. Fourth, documentation supervision program from Field Nursing and internal care are not optimal. Fifth, the integrated assessment format is not practical. Sixth, the documentation does not use the electronic-based system.

Nurses' comprehension and compliance related to documentation require support from nursing leaders. The nurses acknowledge that nursing documentation is an important element to provide quality nursing care. However, several problems, such as lack of supervision, competency issues, and self-confidence and motivation, influence the way they behave towards documentation (13). Thus, the support and improvement of nursing documentation-related skills are undoubtedly important to improve adherence of appropriate nursing documentation.

Outpatients at RSAB X acknowledge that documenting nursing care is an important aspect of the nursing process. However, they have a lack of time to perform the documentation procedures and to balance their other tasks. The nurses' time constraints have an impact on documentation $(3,14)$. Nurses spent an average of $20.9 \%$ of their working hours to do nursing documentation (15). Documentation of nursing care is important in outpatient care, even though the nurses are busy and only have a short time while serving patients.

Training on documentation of nursing care in outpatient care has not been conducted. The Department of Nursing informs that nursing documentation training was conducted in 2016-2018, but the training did not specifically discuss documentation in outpatient care.

Efforts to achieve better documentation require ongoing leadership support and leadership roles to evaluate nursing documentation (4), Several efforts to build competent staff are performed by composing nursing care documentation materials in outpatient care that is discussed in a nurse orientation program and ongoing training $(4,9)$. A previous study showed that nursing staff training plays an important role to improve nursing service documentation (15). A study of Lindo (2016) states that besides guidelines or standards, training and outreach program to document and correct documentation discrepancies are necessary to deal with weaknesses in documenting nursing care at the national level, During the training, techniques and steps to write clear notes according to documentation guidelines and principles that can improve the accuracy of records and increase the possibility of patient care are delivered (5).

Supervision has not been programmed, and its implementation by Clinical Instructors (CI) has not run optimally about the number of patients and lack of time for supervision. Nurses state that if the supervision or audit process is irregular, the right documentation is still difficult to implement. A study by Kamil (2018) supports that nurses are aware of the importance of documentation and claim that they lack an audit or supervision process (13). Supervision is a planned coaching activity to help nursing staff perform their duties effectively (16). Supervision coordinates care and management actions which support the completeness of care and stimulates positive attitudes towards teamwork and contribution, shared responsibility, and development of workplace education (17). Nursing supervision can help nurses improve the completeness of care documentation. Clinical Instructors and Scheduled or unscheduled Nursing Fields can perform new supervision. When scheduled supervision is carried out, accurate results will describe changes in nursing care documentation because 
supervised nurses are well prepared. Unscheduled supervision shows the true condition of documentation.

Supervision, as part of performing control functions, is measured by employing predetermined standards and decided actions to overcome incompatibility between standards and actual performance (18). Supervision needs to use references to obtain a picture of non-conformity, which then becomes the basis for improvement.

The format of nurses' assessment documentation is overwhelming, and thus, it increases the nurses' burden. Better documentation can be achieved not only by building a competent staff or designing nursing documentation material in nurse orientation programs and ongoing training, but also by redesigning the nursing documentation format (19). Changes to the document format must be more efficient, and it can be implemented by using a shorter POR model documentation format (6).

Documentation of nursing at RSAB X has not used electronic documentation. Documentation of manual nursing care has many shortcomings, and thus, it is necessary to consider the use of information technology. The obstacle in documenting nursing is the complexity of the nursing care documentation system because the documentation is still manual (6). The documentation of nursing care using electronics is designed to improve the quality of nursing care and is better than paper-based documentation $(11,15)$. Provision of information technology is needed to optimize documentation of nursing care because it can reduce side effects and medical errors as to improve patient safety and quality of care (20-21). Documentation of nursing care at RSAB X necessarily utilizes electronic documentation, and it is by the plan of using SIRS in RSAB X, which was designed in September 2017 and implemented with priority outpatient areas.

Documentation facilitates communication and collaboration, regulates nursing care chains, makes decisions about patients' care and safety, and ensures professional accountability (15). A strategy is needed, and thus, the implementation of documentation of nursing care is more optimal in outpatient care. Nurses in the nurse station and in the polyclinic to ensure the completeness perform organizing tasks for documentation.

The interview with the Department of Nursing reveals that the implementation of nursing care documentation in outpatient care is not optimal. This statement is in line with the authors' fishbone analysis showing that nursing care documentation does not follow hospital standards/regulations, with the cause of nurses' comprehension and compliance related to nursing care documentation, high workload, unimplemented training programs on specific outpatient documentation. The supervision program of documentation from the Nursing and Internal Field is outpatient and non-optimal. Furthermore, the integrated assessment format is not practical, and the documentation does not employ an electronic system. Optimal documentation of outpatient nursing care is not potentially identified and cannot monitor treatment plans and changes in the patient's condition

\section{Conclusion and Recommendation}

All responsible parties necessarily accomplish the non-optimal documentation of nursing care to the quality of nursing care documentation in outpatient units. The result of the cause root analysis provides several recommendations: 1) arranging scheduled and non- scheduled program and supervision for nursing care documentation in outpatient units conducted by nursing sectors, heads of nurse, and clinical instructors;2) arranging tools of supervision for nursing care documentation; 3) 
arranging an effective, efficient, and accreditation-based documentation format for patients' assessment; 4) resocializing policies and technical documentation, and 5) organizing the staff and time of implementing nursing care documentation in outpatient units.

\section{References:}

1. ANA. ANA's Principles for Nursing Documentation Guidance for Registered Nurses [Internet]. 2010. Available from: www.Nursingworld.org

2. Potter\&Perry. Fundamentals of Nursing Concepts, Process and Practice. 2005;2.

3. Hariyati. Perencanaan Pengembangan dan Utilisasi Tenaga Keperawatan. Jakarta: PT Raja Grafindo Persada.; 2014.

4. Doncliff BB. Improving the quality of nursing notes. 2015;21(6):27-30.

5. Kent P, Better MK, Kent P, Morrow K. Better documentation improves patient care. 2014;29(14):44-51.

6. Ardeny. Efektifitas Format Pendokumentasian Keperawatan Model Problem Oriented Record ( POR ) Terhadap Kemudahan Penggunaannya oleh Perawat. J Kesehatan, VII(3), 366-376. 2016;VII(3):366-76.

7. Phillips J. Nursing Practice Research Change management tools. Nurs Times [Internet]. 2013;1613(15):18-20. Available from:

https://www.cms.gov/medicare/provider-enrollment-and-

certification/qapi/downloads/fishbonerevised.pdf\%0Ahttps://www.cms.gov/Med icare/Provider-Enrollment-and-

Certification/QAPI/downloads/FishboneRevised.pdf

8. Kane R. How to Use the Fishbone Tool for Root Cause Analysis. Qapi [Internet]. 2012;1-3. Available from: https://www.cms.gov/medicare/provider-enrollmentand-

certification/qapi/downloads/fishbonerevised.pdf\%0Ahttps://www.cms.gov/Med icare/Provider-Enrollment-and-

Certification/QAPI/downloads/FishboneRevised.pdf

9. Joint Commission International. Joint Commission International Accreditation Standards For Ambulatory Care. 2015;3 edition.

10. KARS. Standar Nasional Akreditasi Rumah Sakit. 2018;1.

11. Lindo J, Stennett R, Stephenson-wilson K, Barrett KA, Bunnaman D, Andersonjohnson P, et al. An Audit of Nursing Documentation at Three Public Hospitals in Jamaica. 2016;508-16.

12. Mueller A. The Impact of Standardized Patients on Physical Assessment Skills , Clinical Judgment, and Self- Efficacy in Undergraduate Nursing Students. 2017;

13. Kamil H, Rachmah R, Wardani E. What is the problem with nursing documentation? Perspective of Indonesian nurses. Int $\mathrm{J}$ Africa Nurs Sci [Internet]. 2018;9(September):111-4.

Available from: https://doi.org/10.1016/j.ijans.2018.09.002

14. Salam S, Wihastuti TA, Suharsono T. Workload Relation Based on Workload Assessment With the Completeness of Nursing Care Documentation By Implementing Nurses in the Emergency Department of Rsu. Anutapura Palu and Rsu. Undata Palu. J Ilmu Keperawatan (Journal Nurs Sci. 2018;6(1):88-95.

15. Vafaei SM, Manzari ZS, Amiri Farahani L, Froutan R, Heydari A. Improving Nursing 
Care Documentation in Emergency Department: A Participatory Action Research Study in Iran. Open Access Maced J Med Sci. 2018;6(8):1527-32.

16. Dias L, Chaves $\mathrm{P}$, Aline V, Ii M, Alcântara J, Ii S, et al. Nursing supervision for care comprehensiveness. 2017;70(5):1106-12.

17. Matlock AM, Start R, Care A, Series NI. Perspectives in Ambulatory Care. 2016;34(2).

18. Marquis BL, Huston, Carol J. Leadership Roles and Management Function in Nursing. Vol. 53, Lippincott Williams \& Wilkins. 2012. 1689-1699 p.

19. Kalikwani F. Improving the quality of nursing documentation : An action research project. Orig Res. 2014;1-12.

20. Middleton B, Bloomrosen M, Dente MA, Hashmat B, Koppel R, Overhage JM, et al. Enhancing patient safety and quality of care by improving the usability of electronic health record systems: Recommendations from AMIA. J Am Med Informatics Assoc. 2013;20(E1).

21. Saraswasta IWG, Hariyati RTS. The implementation of electronic-based nursing care documentation on quality of nursing care: A literature review. International Journal of Nursing and Health Services. 2018; 1(2):19-31 